\title{
Technetium-99 and Strontium-90: Abundance Determination at Ultratrace Sensitivity by AMS as Signatures of Undeclared Nuclear Reprocessing Activity

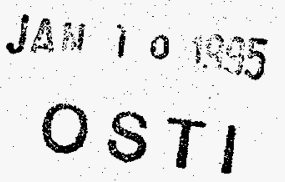 \\ ST as
}

J. E. McAninch

I. D. Proctor 


\section{DISCLAIMER}

This document was prepared as an account of work sponsored by an agency of the United States Government. Neither the United States Government nor the University of California nor any of their employees, makes any warranty, express or implied, or assumes any legal liability or responsibility for the accuracy, completeness, or usefulness of any information, apparatus, product, or process disclosed, or represents that its use would not infringe privately owned rights. Reference herein to any specific commercial product, process, or service by trade name, trademark, manufacturer, or otherwise, does not necessarily constitute or imply its endorsement, recommendation, or favoring by the United States Government or the University of California. The views and opinions of authors expressed herein do not necessarily state or reflect those of the United States Government or the University of California, and shall not be used for advertising or product endorsement purposes.

This report has been reproduced

directly from the best available copy.

Available to DOE and DOE contractors from the

Office of Scientific and Technical Information

P.O. Box 62, Oak Ridge, IN 37831

Prices available from (615) 576-8401, FTS 626-8401

Available to the public from the

National Technical Information Service

U.S. Department of Commerce

5285 Port Royal Rd.

Springfield, VA 22161 


\section{DISCLAMIER}

Portions of this document may be illegible in electronic image products. Images are produced from the best available original document. 


\section{Technetium -99 and Stron tiu m-90:}

\section{A bundance determination at ultratrace sensitivity by AMS as signatures of undeclared nuclear reprocessing activity}

White Paper prepared as part of the 1995 Project Lifecycle Plan update for ST801A in the Regional Monitoring Systems-Effluent Research Program of the DOE Office of Research and Development

J. E. McAninch and I. D. Proctor

Center for Accelerator Mass Spectrometry

Lawrence Livermore National Laboratory

March, 1995

\section{EXECUTIVE SUMMARY}

The purpose of this White Paper is to examine the use of the ultratrace technique Accelerator Mass Spectrometry (AMS) to lower detection limits for ${ }^{99} \mathrm{Tc}$ and ${ }^{90} \mathrm{Sr}$, and to examine the utility of these isotopes as signatures of a covert reprocessing facility. The International Atomic Energy Agency (IAEA) has committed to improving the effectiveness of the IAEA Safeguards System. This is in some degree a result of the discovery in 1991 of an undeclared Iraqi EMIS program. Recommendations from the March 1993 Consultants Group Meeting have resulted in several studies and follow on field trials to identify environmental signatures from covert nuclear fuel reprocessing activity. In particular, the April, 1993 reports of the Standing Advisory Group an Safeguards Implementation (SAGSI) identified the long-lived radioisotopes Technetium-99 and Strontium-90 as two reliable signatures of fuel reprocessing activity. This report also suggested pathways in the chemical processing of irradiated fuel where these elements would be volatilized and potentially released in amounts detectable with ultratrace sensitivity techniques.

${ }^{99}$ Tc can enter the environment via several pathways during the nuclear fuel cycle. The semivolatile species $\mathrm{Tc}_{2} \mathrm{O}_{7}$ and $\mathrm{HTCO}_{4}$ are produced during reprocessing, and the highly volatile species $\mathrm{TcF}_{6}$ is produced during the fluorination of uranium for isotope separation. Estimates of the possible release of ${ }^{99} \mathrm{Tc}$ into the environment from a covert reprocessing facility have been made by McMahon, et al. (Ref. 1 of the text). Based on these estimates, the expected sensitivity of AMS, and the measured environmental levels, examples are given in the text which support the plausibility of ${ }^{99} \mathrm{Tc}$ as a longrange isotopic signature of a reprocessing facility. 
${ }^{90} \mathrm{Sr}$ may also be released from a reprocessing facility in atmospheric emissions and liquid discharges. The mass of ${ }^{90} \mathrm{Sr}$ which is discharged is likely to be smaller than that ${ }^{9}{ }^{99} \mathrm{Tc}$. Technical considerations indicate that this smaller discharge level will be offset by a higher AMS sensitivity for ${ }^{90} \mathrm{Sr} .{ }^{90} \mathrm{Sr}$ is therefore expected to be a plausible signature as well.

Only mass spectrometric techniques have the sensitivity to detect long-lived isotopes at ultratrace levels. The mass spectrometric methods currently used or being developed for the detection of ${ }^{9 \%} \mathrm{Tc}$ are Inductively Coupled Plasma Mass Spectrometry (ICP-MS), Thermal Ionization Mass Spectrometry (TIMS), and Laser Resonance Ionization Mass Spectrometry (RIMS). A review of the literature indicates that ICP-MS does not provide a sensitivity to ${ }^{99} \mathrm{Tc}$ in environmental samples which is competitive with the other techniques. TIMS has the highest demonstrated sensitivity to ${ }^{99} \mathrm{Tc}$ in environmental samples, but suffers from difficult sample preparation and low sample throughput. Both ICP-MS and TIMS are significantly more susceptible to molecular and atomic isobaric interferences than AMS. RIMS shows promise as an ultratrace technique, having exceptional elemental selectivity. However sample preparation and throughput are similar to TIMS, and RIMS does not appear to be sufficiently developed to be useful for the routine detection of environmental samples.

AMS sensitivity is expected to be similar to TIMS sensitivity for environmental samples, but sample preparation chemistry is simpler and sample throughput is much higher. The major technical obstacle in the AMS detection of ${ }^{99} \mathrm{Tc}$ at ultratrace levels is likely to be the lack of a stable technetium isotope. Stable isotopes are important to the high precision and reproducibility of AMS. Several options are available for addressing this obstacle, including the use of chemical carriers, nearby stable elements, and possibly isotope spikes. ${ }^{90} \mathrm{Sr}$ has a much shorter half-life $(29 \mathrm{y})$ than ${ }^{99} \mathrm{Tc}$, and therefore decay counting techniques are relatively more competitive with mass spectrometric techniques. AMS is still expected to have better sensitivity by a factor of 400 over decay counting.

Based on measured ${ }^{99} \mathrm{Tc}$ background levels compiled from a variety of sources, it is estimated that AMS can provide $10 \%$ measurements of environmental levels of ${ }^{99} \mathrm{Tc}$ in a few minutes using modestly sized samples: a few grams for soils, plants, or animal tissues; one to several liters for rain or seawater samples; and tens to hundreds of cubic meters for air sampling. Small sample sizes and high sample throughput result in significant increases in feasibility, cost effectiveness, and quality of data for a regional monitoring program. Similar results are expected for ${ }^{90} \mathrm{Sr}$. 


\section{INTRODUCTION}

The International Atomic Energy Agency (IAEA) has committed to improving the effectiveness of the IAEA Safeguards System. This is in some degree a result of the discovery in 1991 of an undeclared Iraqi EMIS program. Recommendations from the March 1993 Consultants Group Meeting have resulted in several studies and follow on field trials to identify environmental signatures from covert nuclear fuel reprocessing activity [0-3]. In particular, the April, 1993 reports of the Standing Advisory Group on Safeguards Implementation (SAGSI) identified Technetium-99 and Strontium-90 as two reliable signatures of fuel reprocessing activity. This report also suggested pathways in the chemical processing of irradiated fuel where these elements would be volatilized and potentially released in amounts detectable with ultratrace sensitivity techniques.

Long-range or environmental monitoring of nuclear proliferation activity depends on the availability of signature chemical or nuclear isotopes, the ability to distinguish these signals from naturally occurring or anthropogenic backgrounds, and finally to attribute these signals to a covert source. The threshold of activity to be detected is taken as the production of a Significant Quantity of nuclear material as defined by the IAEA. Fuel reprocessing facilities are thought to be the only facilities for which long-range monitoring is practical, because the natural occurrence of uranium is likely to mask any small scale extraction or enrichment activity. The technical means to be considered here is the measurement of two isotopic signatures which are likely to be released into the environment during reprocessing operations. Since it is likely that active measures would be taken to reduce or obscure emissions from such a facility, only small quantities of materials are expected to be released. The feasibility of detecting isotopic signatures therefore depends strongly on the sensitivity of the technique employed.

The purpose of this White Paper is to examine the use of the ultratrace technique Accelerator Mass Spectrometry (AMS) to lower detection limits for two signature isotopes which have previously been measured by other methods. The signatures addressed are the long-lived radioisotopes ${ }^{99} \mathrm{Tc}$ and ${ }^{90} \mathrm{Sr}$. Section 2 of the report covers Technetium, and is divided into three subsections: ${ }^{99} \mathrm{Tc}$ in the environment; currently available techniques for the detection of small quantities of ${ }^{99} \mathrm{Tc}$; and estimates of the sensitivity of AMS for the detection of ${ }^{99} \mathrm{Tc}$ from a covert reprocessing facility. Section 3 covers Strontium. 


\section{TECHNETIUM-99}

\section{A. Release, Transportation, and Occurrence}

Technetium-99 is an abundant product of the nuclear fuel cycle. Lying at the low-mass peak in the ${ }^{235} \mathrm{U}$ fission fragment spectrum, ${ }^{99} \mathrm{Tc}$ accounts for $\sim 10 \%$ of the fission product mass in nuclear fuels following burn-up in a reactor [6]. Because of its long half-life $\left(t_{1 / 2}=2.13 \times 10^{5} \mathrm{y}\right)$, the ${ }^{99} \mathrm{Tc}$ fraction of the radionuclide inventory increases with time as other shorter-lived isotopes decay.

${ }^{99} \mathrm{Tc}$ can enter the environment via several pathways during the nuclear fuel cycle [1]. The semivolatile species $\mathrm{Tc}_{2} \mathrm{O}_{7}$ and $\mathrm{HTCO}_{4}$ are produced during reprocessing [1], and the highly volatile species $\mathrm{TcF}_{6}$ is produced during the fluorination of uranium for isotope separation [6]. ${ }^{99} \mathrm{Tc}$ is also found in airbome particulates and liquid wastes, and is present as an impurity in uranium oxide from irradiated fuels [6]. McMahon, et al. [1] estimate that the release of ${ }^{99} \mathrm{Tc}$ to the environment through liquid discharges from a small covert reprocessing facility could be on the order of $10^{10} \mathrm{~Bq}$, or $\sim 16 \mathrm{~g}$.

Under non-reducing conditions, technetium is highly mobile as the pertechnate ion $\mathrm{TcO}_{4}^{-}$, which allows technetium to be transported throughout the environment, ranging from the atmosphere to groundwater [1]. Under reducing conditions, $\mathrm{Tc}$ is easily sorbed onto inorganic sediments as $\mathrm{TcO}(\mathrm{OH})_{2}$.

Technetium is readily taken up by several plant species. Lichens and mosses can extract technetium from air-borne emissions [6]. Algaes and seaweeds are effective bioaccumulators in marine settings, concentrating technetium by several orders of magnitude $[10,14]$.

Because of its high abundance as a fission product, potential for release to the environment, ubiquitous transport, and the wide variety of materials available for sampling, ${ }^{9} \mathrm{Tc}$ has potential for use in the detection of covert nuclear operations. For this same reason, background levels from nuclear testing and nuclear power operations are significant. As with other isotopic signatures, monitoring activities would be intended to detect increases in the signature above background levels.

Many estimates and measurements of ${ }^{99} \mathrm{Tc}$ in the environment have been published which provide points of reference. A survey of values from different locations and times, and for different sample types is shown in Table 2 of Sec. C. 


\section{B. Detection Techniques}

A summary of detection methods and corresponding detection limits for ${ }^{99} \mathrm{Tc}$ is given in Table 1. Details of the methods are discussed in the following subsections.

TABLE 1. Methods for the detection of ${ }^{99} \mathrm{Tc}$.

\begin{tabular}{lcc}
\hline \hline & detection limits & references \\
analytical method & $1-20 \mathrm{mBq}$ & {$[1,10,24]$ and ref. therein } \\
gas flow GM counting & $1-25 \mathrm{mBq}$ & {$[1,10,14,26]$ and ref. therein } \\
liquid scintillation counting & $3-5 \mathrm{mBq}$ & {$[1,10,22]$} \\
neutron activation analysis & $3 \mu \mathrm{Bq}^{\ddagger}-15 \mathrm{mBq}$ & {$[1,10,11-13,15-17]$} \\
& $5 \mu \mathrm{Bq}^{\ddagger}$ & {$[23,31]$} \\
$\begin{array}{l}\text { ICP-mass spectrometry } \\
\text { thermal ionization mass } \\
\text { spectrometry (TIMS) }\end{array}$ & $1 \mu \mathrm{Bq}^{\ddagger}$ & {$[8,27-29]$} \\
$\begin{array}{l}\text { resonance ionization mass } \\
\text { spectrometry (RIMS) }\end{array}$ & $0.1-50 \mu \mathrm{Bq}$ & (estimated - see Sec. II.B.6) \\
accelerator mass & & \\
spectrometry (AMS) &
\end{tabular}

${ }^{\dagger} 1 \mathrm{mBq}=1.6 \mathrm{pg}, 1 \mu \mathrm{Bq}=1.6 \mathrm{fg}$.

The lowest reported values are instrument limits. Detection limits for environmental samples are likely to be higher.

\section{Decay Counting}

${ }^{99} \mathrm{Tc}$ is a weak beta emitter with low specific activity $(0.63 \mathrm{~Bq} / \mathrm{ng})$ which is difficult to detect at ultratrace levels by decay counting. Detection limits of a few $\mathrm{mBq}$ per sample can be obtained using gas flow Geiger-Müller counting with counting times of several hours. Significant sample preparation chemistry is required to remove interfering radionuclides and to prepare the samples for counting. Liquid scintillation counting (LSC) reaches similar detection limits, but has the advantage that sample preparation is simpler and interferences from other radionuclides can be rejected to some extent.

\section{Neutron Activation Analysis (NAA)}

Trace amounts of ${ }^{99} \mathrm{Tc}$ can be detected by neutron activation analysis [22]. Thermal neutron capture on ${ }^{99} \mathrm{Tc}$ produces the short-lived isotope ${ }^{100} \mathrm{Tc}\left(\mathrm{t}_{1 / 2}=15.8 \mathrm{~s}\right)$, which can be readily detected by betaspectrometry. NAA requires that the sample be highly purified to avoid the activation of other isotopes. The short half-life also results in quantification difficulties at most NAA facilities. A mechanism is required for the rapid retrieval and counting of the sample, and both the irradiation time 
and the time for retrieval from the reactor must be well-determined for quantitative analysis.

\section{Mass Spectrometric Atom Counting Techniques - General Considerations}

For the ultratrace analysis of ${ }^{99} \mathrm{Tc}$, mass spectrometric atom counting techniques are required. Atom counting techniques offer three significant advantages in the detection of long-lived radionuclides. 1) Detection sensitivity and measurement time, typically a few minutes to a few hours, do not depend on the half-life of the isotope. 2) Detection sensitivity does not depend on the energy or type of radiation, allowing weak emitters to be detected the same efficiency as high energy emitters. 3) Atom counting techniques are free from interferences associated with the decay emissions of other radionuclides present in the sample. Detection sensitivity therefore does not depend an the total activity present in the sample (providing the total activity does not constitute an exposure risk to the analyst), simplifying the chemical preparation.

Atom counting techniques which have been applied to the ultratrace detection of ${ }^{99} \mathrm{Tc}$ are inductively coupled plasma mass spectrometry (ICP-MS), thermal ionization mass spectrometry (TIMS), and laser resonance ion ionization mass spectrometry (RIMS). Accelerator mass spectrometry (AMS) also falls into this category.

The two major considerations in atom counting techniques are sample preparation and interferences from molecular and atomic isobars. Samples must be put into a form which provides efficient ion production and an appropriate sample size, and major matrix elements may need to be removed if they degrade the performance of the apparatus. Adjustments to the sample form may also be necessary to reduce cross-contamination between consecutive samples ("memory" effects). Finally, the sample preparation must minimize the level of molecular and atomic isobars in the sample. The ability to remove or account for these interferences in the spectrometer differs between techniques and for different isotopes. In the detection of ${ }^{99} \mathrm{Tc}$, the major isobaric interference is from ${ }^{99} \mathrm{Ru}$, a stable isotope of Ruthenium. Fortunately, Ruthenium is not abundant in nature, and chemical separation procedures have been developed which allows the further suppression of Ruthenium relative to Technetium by 4-5 orders of magnitude $[11,15,17,32] .{ }^{99} \mathrm{Ru}$ is also a fission product however, and highly volatile species of Ruthenium are produced in the nuclear fuel cycle $[1,2]$. Therefore, ${ }^{99} \mathrm{Ru}$ must be kept in consideration.

\section{Inductively Coupled Plasma Mass Spectrometry (ICP-MS)}

Inductively coupled plasma mass spectrometry has the capability to detect ultratrace levels of ${ }^{99} \mathrm{Tc}$. In ICP-MS, samples in aqueous solution are introduced as vapor droplets into a high temperature Argon plasma $(6000-7000 \mathrm{~K})$, where the sample is ionized. The resulting ions are subsequently accelerated to a few tens of kilovolts, analyzed in an electrostatic and/or magnetic mass spectrometer, and the individual ions counted. Sensitivity and precision depends on the specific type of ionizer and 
spectrometer employed.

ICP-MS provides quick measurements (minutes per sample), minimal downtime between samples, and the ability to rapidly cycle through several masses, providing simultaneous multielement analysis. The primary disadvantage of ICP-MS is that interferences from atomic and molecular isobars must be removed through sample preparation, although interferences can be subtracted as a background by analysis of the mass spectra. A further challenge of the sample preparation chemistry is that heavy matrix elements in the sample must be removed to a fairly high degree to avoid clogging the apparatus or degrading the ionization efficiency.

Instrumental blank levels have been demonstrated corresponding to $\sim 1-10 \mu \mathrm{Bq}{ }^{99} \mathrm{Tc}$ per sample [1113,15,16]. For the measurement of environmental samples these authors applied preconcentration techniques to extract ${ }^{99} \mathrm{Tc}$ from relatively large samples, typically yielding activities of $0.1-100 \mathrm{mBq}$ per sample measured. In most cases, these authors quoted relative uncertainties of $20-30 \%$, independent of the activity of the sample.

\section{Thermal Ionization Mass Spectrometry (TIMS)}

The highest demonstrated sensitivity for ${ }^{99} \mathrm{Tc}$ has been obtained using thermal ionization mass spectrometry [23,31]. TIMS differs from ICP-MS primarily in the method of ionization. In TIMS, a few microliters of sample solution are placed onto a Rhenium filament and dried. The filament is then heated in a controlled manner, ionizing the sample. As with ICP-MS, the sensitivity and precision depends on the specific type of ionizer and spectrometer employed.

TIMS is in general susceptible to similar interferences as ICP-MS, and similar spectrometers are used. However, ionization efficiency is much higher, allowing significantly smaller quantities of material to be analyzed. The major drawback of TIMS is that measurement times are typically one to several hours per sample, so that only a few samples per day can be measured. A further drawback is that filament preparation is time-consuming and requires careful attention. Additives are often necessary to enhance the ionization efficiency.

Rokop, et al. [23] report TIMS measurements of ${ }^{99} \mathrm{Tc}$ for samples containing as low as $5 \mu \mathrm{Bq}(\sim 7 \mathrm{fg})$. For quantification of the results, isotope dilution with an $18 \mathrm{pg}{ }^{97} \mathrm{Tc}$ spike was used. The measured ion was $\mathrm{TcO}_{4}^{-}$. An isobaric background was observed which was attributed to an unidentified Molybdenum molecule. This background was subtracted from the results using the natural isotopic abundances for Mo. For the $5 \mu \mathrm{Bq}$ test samples, this background was approximately equal in intensity to the $\mathrm{TcO}_{4}^{-}$signal. In a subsequent work [31], this technique was applied to the detection of ${ }^{99} \mathrm{Tc}$ in ground water at the Nevada Test Site. The samples ( 2001 each) contained 100-250 fg (50-150 $\mu \mathrm{Bq})$ of ${ }^{99} \mathrm{Tc}$. Measurement uncertainty was reported at $7-12 \%$. 


\section{Laser Resonance Ionization Mass Spectrometry (RIMS)}

Laser resonance ionization mass spectrometry has recently been explored by a research group at Universität Mainz for the ultratrace detection of ${ }^{98} \mathrm{Tc}$ and ${ }^{99} \mathrm{Tc}[8,27-29]$.

Samples are treated chemically to remove contaminants, resulting in Technetium in aqueous solution. The technetium is then electroplated onto rhenium or tungsten filaments, which are placed into the spectrometer. The filaments are heated to $\sim 2300 \mathrm{~K}$, evolving neutral Technetium atoms. A set of three tuned lasers illuminate the beam, selectively exciting the Technetium atoms to progressively higher levels, ultimately resulting in photoionization. The ions are then accelerated electrostatically to $\sim 3 \mathrm{keV}$. The ions pass along a drift tube and are detected by a microchannel plate. Since the lasers are pulsed, the time of photoionization is known. The drift time, and therefore the mass of the ion can be determined.

The Mainz researchers applied this technique to the measurement of known samples containing as few as $10^{8}$ atoms of ${ }^{99} \mathrm{Tc}(\sim 10 \mu \mathrm{Bq})$. They reported an overall efficiency for their system of $2 \times 10^{-6}$, implying an instrumental detection limit of $\sim 1 \mu \mathrm{Bq}$. Further improvements in the apparatus are expected to lower this limit by a factor of 10 .

Because of the high elemental selectivity, RIMS shows promise for the ultratrace detection of ${ }^{99} \mathrm{Tc}$. Based on the references examined [8,27-29], the primary focus of this group is the detection of all three long-lived Technetium isotopes in Molybdenum ores as a measurement of the solar neutrino flux. This endeavor will require significant improvement in their detection capabilities, particularly with respect to Molybdenum interferences. It appears that most of the effort has been aimed at technical improvements, and little emphasis has been placed on measurements of environmental samples using the apparatus as is. Therefore, it is difficult at this time to estimate the usefulness of RIMS for environmental work or for the routine measurement of large numbers of samples.

\section{Accelerator Mass Spectrometry (AMS)}

Accelerator mass spectrometry is an ultrasensitive technique for the detection of rare isotopes, typically long-lived radioisotopes which cannot be readily detected by decay counting. AMS is now routinely applied to the ultratrace detection of rare isotopes in a wide range of fields. Products of nuclear fuel reprocessing which are routinely detected by AMS are ${ }^{14} \mathrm{C},{ }^{36} \mathrm{Cl}$, and ${ }^{129} \mathrm{I}$. Often $50-100$ samples per day are measured, and a precision of $10 \%$ or better can be obtained for samples containing $\sim 1 \times 10^{6}$ atoms of the rare isotope. Rare to stable isotope ratios can be as low as $10^{-14}-10^{-15}$.

Samples are prepared as a solid matrix, consisting of an appropriate compound of the element of interest. A metallic carrier such as Silver is often included to help stabilize the sample in the ion source. Typically the final prepared sample form consists of $\sim 1 \mathrm{mg}$ of material, including metallic carrier, packed into an appropriate target holder. The sample is ionized using a Cesium sputter ion 
source, and the resulting negative ions are injected into a tandem Van de Graaff accelerator. Electrons are stripped from the ions in the accelerator, and any molecular ions are broken up. The ions exit the accelerator as multiply-charged positive atomic ions with 1-200 MeV of energy, depending on the ion and accelerator. Following post-accelerator analysis in the high-energy mass spectrometer, the rare ions are counted individually in a particle detector, typically a gas ionization detector. The stable ion currents after the accelerator are measured simultaneously or quasi-simultaneously with the rare ions. The result is a measurement of the rare-to-stable isotope ratio. Comparison to standards yields the absolute mass of rare isotope in the sample.

AMS offers two distinct advantages in background rejection compared to other mass spectrometric techniques. The first is the destruction of molecular isobars during the charge stripping process. The second is the ability to identify the individual ions following analysis in the spectrometer. Because the ions are accelerated to $\mathrm{MeV}$ energies, nuclear physics detection techniques can be used for particle identification, allowing further, post-spectrometer rejection of remaining backgrounds. For most AMS isotopes, these rejected backgrounds consist primarily of stable atomic isobars of the isotope of interest. An example is ${ }^{36} \mathrm{~S}$ interference in the detection of ${ }^{36} \mathrm{Cl}$, which can be rejected by 4 to 5 orders of magnitude. (The stable isobars of ${ }^{14} \mathrm{C}$ and ${ }^{129} \mathrm{I}$ do not form negative ions and cannot be detected.) For most isotopes, interferences are sufficiently reduced by the combination of spectrometry and particle identification that no background subtraction is needed. Sensitivity is then usually limited by background levels of the rare isotope - either natural levels or contamination introduced during sample preparation.

The estimated sensitivity for AMS detection of ${ }^{99} \mathrm{Tc}$ is included in Table 1. The lower limit of $0.1 \mu \mathrm{Bq}$ is based an known information about the efficiency of the accelerator, and the ionization efficiency which is expected for Technetium [30]. The higher limit ( $50 \mu \mathrm{Bq})$ accounts for possible difficulties which may be encountered resulting from the stable isobar ${ }^{99} \mathrm{Ru}$ (see below). The listed limits were estimated assuming measurement times of 15-30 minutes per sample.

The detection of ${ }^{99} \mathrm{Tc}$ by AMS presents some challenges which do not exist for AMS other isotopes. The most significant of these is the lack of a stable Tc isotope. The high precision of AMS, in terms of reproducibility and systematic errors, is largely made possible by the quasi-simultaneous injection of the stable isotope through the accelerator, which allows time- and sample-dependent variations in the efficiencies of the ion source, accelerator, and spectrometer to be accounted for implicitly in the isotope ratio. Sample-to-sample variations in yields for sample preparation chemistry drop out also. This allows AMS measurements to be made at few percent to fraction of a percent precision when sufficient counting statistics are available.

There are several approaches which can be employed to address the lack of a stable Technetium isotope. Rhenium, a chemical analog of Technetium, could be added in the sample preparation to act as a chemical carrier for the small amount of Technetium present. To provide a stable isotope for the 
isotope ratio, the samples would need to be packed in a matrix of some other element, probably Rhodium, which could act as a surrogate for a stable Technetium isotope. ${ }^{97} \mathrm{Tc}$ spikes could also be added to the samples and counted as well, as is done in the TIMS measurements.

A second possible difficulty is the stable atomic isobar ${ }^{99} \mathrm{Ru}$. As with ICP-MS and TIMS, AMS will be sensitive to background from ${ }^{99} \mathrm{Ru}$. As discussed above, stable isobars can be rejected for lighter AMS isotopes, such as ${ }^{36} \mathrm{Cl}$. The smaller relative difference in atomic number between ${ }^{99} \mathrm{Tc}$ and ${ }^{99} \mathrm{Ru}$ prevents these isobars from being separated in an ionization detector [4]. Based an the low abundance of Ruthenium in nature, and the success of chemical procedures for separating Technetium and Ruthenium $[11,15,17,32],{ }^{99} \mathrm{Ru}$ interference in prepared samples is expected to be small.

In the event that ${ }^{99} \mathrm{Ru}$ interference is substantial, characteristic $X$-rays can be used to detect the ions [4]. This technique, designated as PXAMS, would allow rejection of ${ }^{99} \mathrm{Ru}$ ions after detection by a factor of $\sim 200$, but would result in a factor of $\sim 1000$ reduction in detection efficiency. The effect of this on the ultimate detection sensitivity would be to raise the minimum detection limit from $\sim 0.1 \mu \mathrm{Bq}$ to $\sim 50 \mu \mathrm{Bq}$.

The drawbacks listed here for AMS apply to some extent to the other techniques. For instance, while the presence of ${ }^{99} \mathrm{Ru}$ could substantially degrade the AMS detection sensitivity, AMS will have a higher rejection of this isobar than either ICP-MS or TIMS. Therefore, for a given sample, AMS can be expected to have a similar or lower detection sensitivity than the ICP-MS or TIMS. AMS is also less sensitive to most minor matrix elements than these techniques, so sample preparation is in general simpler.

Because of its high elemental selectivity, RIMS is likely to be significantly less sensitive to isobaric interferences than any of the other techniques, including AMS. However, the overall detection efficiency is similar to AMS using a gas ionization counter, so that the statistical limits are similar. In addition, RIMS has not yet been proven for routine detection of samples, or for the detection of Technetium in environmental samples.

We estimate that the ${ }^{99} \mathrm{Tc}$ activity required for routine determination by AMS is approximately $100 \mu \mathrm{Bq}$ (=160 fg or $1 \times 10^{6}$ atoms). Much smaller activities could be detected, but at this level $\sim 10 \%$ measurements would be obtained in 15 minutes per sample. This estimate assumes that the measurements are made using characteristic $X$-ray detection. Using this detection method, the final prepared samples could contain ${ }^{99} \mathrm{Ru}$ at levels as large as 100-1000 times the ${ }^{90} \mathrm{Tc}$ level and still be measureable. If ${ }^{99} \mathrm{Ru}$ can be sufficiently removed, as is suggested by the ICP-MS and TIMS results, then the gas ionization detector could be used, improving the detection efficiency by a factor of $\sim 1000$. This would allow measurement times to be reduced to $<5 \mathrm{~min}$., and the sample sizes could be further reduced by a factor of 10-100.

To summarize, AMS is expected to provide similar or better sensitivity to ${ }^{99} \mathrm{Tc}$ as TIMS, but with simpler sample preparation and substantially reduced measurement time. For environmental samples, AMS is expected to provide better sensitivity than has been reported for ICP-MS measurements, based 
on the reviewed literature. AMS is not sensitive to molecular isobars which can interfere with the other techniques. In the event that substantial amounts of ${ }^{99} \mathrm{Ru}$ are found in samples that cannot be sufficiently removed in sample preparation, AMS will have the capability to reject this isobar by a factor of $\sim 200$ better than ICP-MS or TIMS. Based on the reviewed literature, RIMS does not appear to be sufficiently developed for the routine detection of ${ }^{99} \mathrm{Tc}$ in environmental samples. AMS is also expected to require simpler sample preparation and shorter measurement times. 


\section{AMS applied to the detection of ${ }^{99} \mathrm{Tc}$ from a covert reprocessing facility}

The intent of a ${ }^{99} \mathrm{Tc}$ monitoring program would be to detect increases in ${ }^{99} \mathrm{Tc}$ levels above background. An estimate of the sensitivity of monitoring therefore requires knowledge of the expected environmental levels.

A survey of measured ${ }^{99} \mathrm{Tc}$ activities from a variety of environmental sources is shown in Table 2 . In general, these samples are expected to be representative of worldwide levels resulting from fallout. For the most part, they do not represent the elevated levels which might be found in the immediate vicinity of a nuclear facility. One notable exception to this are the seaweed samples taken near Greenland, Norway, and the W. Scottish Coast, which show highly elevated "Tc caused by emissions from the Sellafield reprocessing plant. Also noteworthy is the very large increase in ${ }^{90} \mathrm{Tc}$ found in rainwater in Monaco in the 2-3 months following the Chernobyl accident.

When reported, the measurement technique and sample sizes required are included in Table 1 . A large number of the listed measurements came from Ref. 14. Since no sample sizes were reported in the reference, estimates of minimum samples sizes (marked as ?) have been included in the table for comparison. The estimated minimum sample sizes assume an activity of $10 \mathrm{mBq}$ per sample, which is 10 times the minimum detectable activity reported by the authors for a $24 \mathrm{hr}$ counting period.

Also included in Table 2 are estimates of the appropriate sample sizes for routine measurement by AMS (rightmost column), assuming a sample ${ }^{99} \mathrm{Tc}$ activity of $0.1 \mathrm{mBq}$ (see Sec. II.B.6). This value could be lowered by as much as a factor of 100 if ${ }^{99} \mathrm{Ru}$ interference in prepared samples is small, as is expected from ICP-MS and TIMS results. The sample size estimates in Table 2 indicate that only modest quantities of sample material would be required for the detection of ${ }^{99} \mathrm{Tc}$ at current environmental levels. Sample sizes are a few grams for soil, plant or tissue samples; less than 1 liter in most cases for rain or water samples; and only a few hundred cubic meters for air samples. The quantities required for AMS are typically a factor of 100 smaller than that needed for decay counting measurements. The largest volumes listed are 100-200 $\ell$ for water samples in which the activity is a few $\mu \mathrm{Bq}$ per liter.

Sample collection, storage, transportation, and preparation would be relatively convenient given the small quantities needed, even for a large number of samples. Samples would require minimal processing in the field, and multiple aliquots could be easily obtained for repeat analyses, targeted analysis for other analytes, cross-checking between labs, and archival storage. All of these factors increase the feasibility and cost effectiveness of the monitoring program, and enhance the quality of the data acquired.

The probability of an accidental release, at levels which could be detected by a regional monitoring program, is a more difficult question to address. This probability is very site-dependent, both in terms of the design and operation of the facility, and of the local geology and hydrology. A thorough study is 
beyond the scope of this report. However, some basic numbers can be estimated.

McMahon, et al. [1] estimate that the release of ${ }^{99} \mathrm{Tc}$ to the environment through liquid discharges from a small covert reprocessing facility could be on the order of $10^{10} \mathrm{~Bq}$, or $\sim 16 \mathrm{~g}$. This estimate was based on a release fraction for ${ }^{99} \mathrm{Tc}$ of $\sim 5 \%$, which was the observed release to liquid discharges from the Sellafield reprocessing facility in 1991. At a covert facility, it is likely that more intense effort would be made to reduce emissions. For a starting point, a more conservative release fraction might be $5 \times 10^{-4}$, implying a total release of $10^{10} \mathrm{~Bq}$.

The definition of a "clean" signal will depend on precision of the detection method, the quantity and quality of the pre-release background data that has been acquired, and the size of the variation in the local background. For purposes of estimation, a plausible definition of a "clean" signal is a doubling of the activity above background. Substantially smaller signals, possibly even a $10 \%$ change, could conceivably be "clean" under some circumstances, for instance if the local background is quite constant, or if a small signal was simultaneously seen in several signatures or at several monitoring sites.

To estimate the sensitivity to a liquid discharge, the following assumptions will be used: a "clean" signal results from a doubling of the pre-release background; the pre-release background is $1 \mathrm{mBq} / \ell$; and the activity is uniformly distributed through the water volume. For a release of $10^{8} \mathrm{~Bq}$, the volume of water meeting these assumptions is $10^{8} \mathrm{~m}^{3}$. For reference, this is the equivalent of a lake which is $\sim 3$ $\mathrm{km}$ across and $20 \mathrm{~m}$ deep.

This volume of water could also be represented as a $50 \mathrm{~km}$ section of a river which is $10 \mathrm{~m}$ deep and $200 \mathrm{~m}$ wide. Building on this model, some further assumptions can be made. Suppose the release was the result of a spill, that the entire $10^{8} \mathrm{~Bq}\left(100 \mathrm{mg}\right.$ of $\left.{ }^{99} \mathrm{Tc}\right)$ reached the river in the span of a few hours, and that the average flow of the river was $1 \mathrm{~m} / \mathrm{s}$. A significant probability of detecting this spill could be obtained with a monitoring program which took one $250 \mathrm{ml}$ sample every $12 \mathrm{hrs}$ at a fixed point down river from the spill.

Air monitoring could also be used for the detection of ${ }^{99} \mathrm{Tc}$. Assuming a pre-release background of $1 \mu \mathrm{Bq} / \mathrm{m}^{3}$, and an air volume of $100 \mathrm{~km}$ by $100 \mathrm{~km}$ by $1000 \mathrm{~m}$ high, a regional monitoring program could detect a release of $\sim 10^{7} \mathrm{~Bq}(16 \mathrm{mg})$. This corresponds to a release faction of $\sim 5 \times 10^{-5}$ for a small reprocessing facility. Sufficient sample material could be obtained from $100 \mathrm{~m}^{3}$ of air, which could be processed by a low capacity sampler in $\sim 1$ day.

The examples given here are admittedly simplistic. However, they are intended to give an idea of the scale of ${ }^{99} \mathrm{Tc}$ monitoring which would be possible using accelerator mass spectrometry. 
TABLE 2. Environmental levels of ${ }^{99} \mathrm{Tc}$.

\begin{tabular}{|c|c|c|c|c|c|c|c|c|c|}
\hline $\begin{array}{l}\text { Sample } \\
\text { Type }\end{array}$ & Location & Year & Ref. & $\begin{array}{c}\text { Detection } \\
\text { Method }\end{array}$ & $\begin{array}{c}\text { Sample } \\
\text { Size }^{\text {b }}\end{array}$ & & c Activity & $\begin{array}{r}\mathrm{Al} \\
\mathrm{San} \\
\mathrm{Si} \\
\end{array}$ & $\begin{array}{l}\text { MS } \\
\text { nple } \\
\text { ze }\end{array}$ \\
\hline $\begin{array}{l}\text { accumulatea } \\
\text { deposition }\end{array}$ & Sweden & $1961-75$ & 24 & calculated & $>200^{?} \mathrm{~cm}^{2}$ & 500 & $\mathrm{mBq} / \mathrm{m}^{2}$ & 2 & $\mathrm{~cm}^{2}$ \\
\hline surface soils & Japan & ca. 1992 & 11 & ICP-MS & $\sim 250^{\mathrm{b}} \quad \mathrm{g}$ & $100-300$ & $\mathrm{mBq} / \mathrm{kg}$ (dry) & 1 & g \\
\hline lichens & $\begin{array}{l}\text { Sweden/ } \\
\text { N. Europe }\end{array}$ & $1956-81$ & 21 & $\begin{array}{c}\text { GM- } \\
\text { counting }\end{array}$ & $\sim 100 \mathrm{~g}$ & $50-100$ & $\mathrm{mBq} / \mathrm{kg}$ (dry) & $1-2$ & $g$ \\
\hline $\begin{array}{l}\text { animal } \\
\text { tissues }\end{array}$ & Sweden & 1963-81 & 21 & “ & $\sim 100 \mathrm{~g}$ & $20-500$ & $\mathrm{mBq} / \mathrm{kg}$ (dry) & $1-5$ & g \\
\hline air & $\begin{array}{l}\text { Sweden } \\
\text { Monaco }\end{array}$ & $\begin{array}{c}1981 \\
1986^{e}\end{array}$ & $\begin{array}{l}24 \\
24\end{array}$ & “ & $\begin{array}{l}>2 \times 10^{4} ? \mathrm{~m}^{3} \\
>2500^{?} \mathrm{~m}^{3}\end{array}$ & $\begin{array}{r}0.5 \\
3.6^{\mathrm{e}}\end{array}$ & $\begin{array}{l}\mu \mathrm{Bq} / \mathrm{m}^{3} \\
\mu \mathrm{Bq} / \mathrm{m}^{3}\end{array}$ & $\begin{array}{r}200 \\
25\end{array}$ & $\begin{array}{l}\mathrm{m}^{3} \\
\mathrm{~m}^{3}\end{array}$ \\
\hline $\begin{array}{l}\text { natural bkg } \\
\text { groundwater }\end{array}$ & $\begin{array}{l}\text { Nevada Test } \\
\text { Site Aquifer }\end{array}$ & 1981-82 & $\begin{array}{l}31 \\
31\end{array}$ & $\begin{array}{l}\text { calculated } \\
\text { TIMS }\end{array}$ & $\begin{array}{l}\text { NA } \\
\sim 10 \ell \ell\end{array}$ & $\begin{array}{r}<0.6^{c} \\
8-15\end{array}$ & $\begin{array}{l}\mu \mathrm{Bq} / \ell \\
\mu \mathrm{Bq} / \ell\end{array}$ & $\begin{array}{r}200 \\
10\end{array}$ & $\begin{array}{l}\ell \\
\ell\end{array}$ \\
\hline rain water & $\begin{array}{c}\text { Texas } \\
\text { Monaco } \\
\text { Monaco }\end{array}$ & $\begin{array}{c}1967 \\
1985 \\
1986^{\mathrm{e}}\end{array}$ & $\begin{array}{l}24 \\
24 \\
24\end{array}$ & “ & $\begin{array}{rr}>50^{?} & \mathrm{ml} \\
>500^{?} & \mathrm{ml} \\
>0.5^{?} & \mathrm{ml}\end{array}$ & $\begin{array}{r}230 \\
20 \\
20000^{e}\end{array}$ & $\begin{array}{l}\mathrm{mBq} / \ell \\
\mathrm{mBq} / \ell \\
\mathrm{mBq} / \ell\end{array}$ & $\begin{array}{r}<1 \\
5 \\
<1\end{array}$ & $\begin{array}{l}\mathrm{ml} \\
\mathrm{ml} \\
\mathrm{ml}\end{array}$ \\
\hline seawater & $\begin{array}{c}\text { Baltic Sea } \\
\text { Irish Sea } \\
\text { Irish Sea } \\
\text { North Sea } \\
\text { North Sea } \\
\text { Mediterranean } \\
\text { Japan }\end{array}$ & $\begin{array}{c}1986 \\
1969 \\
1972 \\
1980 \\
1981 \\
1985-86 \\
1993\end{array}$ & $\begin{array}{l}25 \\
24 \\
24 \\
24 \\
24 \\
24 \\
13\end{array}$ & $\begin{array}{c}" \\
" \\
" \\
" \\
" \\
\text { ICP-MS }\end{array}$ & $\begin{array}{rl}200 & \ell \\
>2^{?} & \ell \\
>100^{?} & \mathrm{ml} \\
>15^{?} & \ell \\
>3^{?} & \ell \\
>150^{?} & \ell \\
1400-2800 & \ell\end{array}$ & $\begin{array}{r}0.02-2 \\
4.5 \\
108 \\
0.7 \\
3.5 \\
0.07 \\
1-7\end{array}$ & $\begin{array}{l}\mathrm{mBq} / \ell \\
\mathrm{mBq} / \ell \\
\mathrm{mBq} / \ell \\
\mathrm{mBq} / \ell \\
\mathrm{mBq} / \ell \\
\mathrm{mBq} / \ell \\
\mu \mathrm{Bq} / \ell\end{array}$ & $\begin{array}{r}5 \\
25 \\
1 \\
200 \\
30 \\
2 \\
100\end{array}$ & $\begin{array}{l}\ell \\
\mathrm{ml} \\
\mathrm{ml} \\
\mathrm{ml} \\
\mathrm{ml} \\
\ell \\
\ell\end{array}$ \\
\hline $\begin{array}{l}\text { seawater } \\
\text { algae }^{d}\end{array}$ & $\begin{array}{c}\text { Japan } \\
\text { same location }\end{array}$ & $1989-90$ & $\begin{array}{l}14 \\
14\end{array}$ & $\begin{array}{c}\beta- \\
\text { counting }\end{array}$ & $\begin{array}{l}\text { not reported } \\
\text { not reported }\end{array}$ & $\begin{array}{l}0.01-0.2 \\
10^{2}-10^{3} \mathrm{~d}\end{array}$ & $\begin{array}{l}\mathrm{mBq} / \ell \\
\mathrm{mBq} / \mathrm{kg} \text { (wet) }\end{array}$ & $\begin{array}{r}10 \\
1\end{array}$ & $\begin{array}{l}\ell \\
g\end{array}$ \\
\hline seaweed & $\begin{array}{l}\text { W. Norway } \\
\text { W. Scotland }\end{array}$ & $\begin{array}{l}1982 \\
1982\end{array}$ & $\begin{array}{l}24 \\
24 \\
\end{array}$ & $\begin{array}{c}\text { GM- } \\
\text { counting } \\
" \\
\text { " }\end{array}$ & $\begin{array}{ll}>1^{?} & \mathrm{~g} \\
& \\
-1^{2} & \mathrm{~g} \\
<1^{?} & \mathrm{~g} \\
\end{array}$ & $\begin{array}{r}\sim 100 \\
10^{3}-10^{4} \\
\end{array}$ & $\begin{array}{l}\mathrm{Bq} / \mathrm{kg} \text { (dry) } \\
\mathrm{Bg} / \mathrm{kg} \text { (dry) }\end{array}$ & $\begin{array}{l}<1 \\
<1\end{array}$ & $\begin{array}{l}g \\
g\end{array}$ \\
\hline
\end{tabular}

${ }^{2}$ This is the estimated sample size required for AMS measurement to $<10 \%$ statistical uncertainty in $\sim 15 \mathrm{~min}$ per sample. It assumes a ${ }^{99} \mathrm{Tc}$ activity of $0.1 \mathrm{mBq}=0.16 \mathrm{pg}$. See text for further discussion.

bSizes were not reported in Ref. 11, but are estimated here from a description of the sample collection.

${ }^{c} \mathrm{G}$ roundwater in the alluvial aquifer at NTS was estimated to contain a background of $<0.6 \mu \mathrm{Bq} / \ell$, resulting from the spontaneous fission of naturally occurring ${ }^{238} \mathrm{U}(3 \mathrm{ppm})$ in the alluvium.

${ }^{d}$ The algae Sargassum thunbergii concentrated ${ }^{99} \mathrm{Tc}$ from seawater by a factor of $\sim 10,000$.

eSamples taken within 6 mos. following the Chernobyl accident.

'Sample sizes were not reported in Ref. 24. Minimum samples sizes are estimated here by calculating the size required for an activity equal to 10 times the reported detection limit of $1 \mathrm{mBq}$ for a $24 \mathrm{hr}$ counting period. For further discussion see text. 


\section{STRONTIUM-90}

The arguments made in Sec. II for the applicability of ${ }^{9} \mathrm{Tc}$ as a signature isotope, and for the advantages of AMS over other techniques for the detection of ${ }^{99} \mathrm{Tc}$, apply to a large extent to ${ }^{90} \mathrm{Sr}$. Therefore, this section will concentrate on the noteworthy differences.

In their estimate of releases in liquid discharge from a small covert reprocessing facility, McMahon, et al. [1] estimate a similar released activity for ${ }^{90} \mathrm{Sr}$ as for ${ }^{99} \mathrm{Tc}$ - approximately $10^{10} \mathrm{~Bq}$. Because of the much shorter half-life of ${ }^{90} \mathrm{Sr}(28.78 \mathrm{y})$, and the correspondingly higher specific activity $\left(5.3 \mathrm{~Bq} / \mathrm{pg}\right.$ ), this activity equates to a ${ }^{90} \mathrm{Sr}$ mass of only $\sim 2 \mathrm{mg}$, as compared to $\sim 16 \mathrm{~g}$ for ${ }^{99} \mathrm{Tc}$. Hence, for ${ }^{90} \mathrm{Sr}$ to have similar effectiveness as an isotopic signature, the detection sensitivity must be a factor of $\sim 7,000$ better than for ${ }^{99} \mathrm{Tc}$. In addition, the higher specific activity makes decay counting a much more competitive technique in terms of mass sensitivity. An activity of $20 \mathrm{mBq}$, which is the detection limit for decay counting [1], corresponds to $\sim 2 \mathrm{fg}$, or about $1 \times 10^{7}$ atoms. Despite these apparent drawbacks, the detection of ${ }^{90} \mathrm{Sr}$ by AMS can be a significant, sensitive addition to the available suite of isotopic signatures.

The detection of ${ }^{90} \mathrm{Sr}$ by AMS is expected to follow for the most part the techniques used in ${ }^{41} \mathrm{Ca}$ AMS [33]. The stable isobar of ${ }^{90} \mathrm{Sr}$ is ${ }^{90} \mathrm{Zr}$. Zirconium has a relatively low abundance in nature and a high degree of chemical separation of zirconium from strontium samples should be possible. The atomic number of zirconium is two units higher than that of strontium, so any remaining ${ }^{90} \mathrm{Zr}$ in a sample should be reasonably well separated from ${ }^{90} \mathrm{Sr}$ using a gas ionization detector following the spectrometer. Therefore the efficiency loss using characteristic X-ray detection, as may be necessary for ${ }^{99} \mathrm{Tc}$, will not be incurred. For these and other technical reasons, it should be possible to measure ${ }^{90} \mathrm{Sr}$ by AMS to levels which are routinely achieved for the current set of AMS isotopes.

The expected minimum detection limit for ${ }^{90} \mathrm{Sr}$ is $\sim 0.01 \mathrm{fg}$, or $50 \mu \mathrm{Bq}$. This value is similar to the AMS detection limits for other isotopes. It should be possible to make $10 \%$ measurements in 15 mins. of samples containing $\sim 500 \mu \mathrm{Bq}$. AMS is expected to be more sensitive than decay counting by a factor of $\sim 400$. Decay counting of ${ }^{90} \mathrm{Sr}$ also suffers from interferences from ${ }^{89} \mathrm{Sr}\left(t_{1 / 2}=50.5 \mathrm{~d}\right)$ and ${ }^{90} \mathrm{Y}\left(t_{1 / 2}=64 \mathrm{hr}\right)$, the daughter of ${ }^{90} \mathrm{Sr}$, as well as other radionuclides, so that extensive chemical treatment is required. For instance, Wilken and Diehl [34] report a total sample preparation and measurement time of $\sim 20 \mathrm{~d}$, with only 6 samples being processed in parallel.

In terms of activity, the expected discharge and the expected sensitivity are similar for ${ }^{90} \mathrm{Sr}$ as for

${ }^{99} \mathrm{Tc} .{ }^{90} \mathrm{Sr}$ is therefore anticipated to have comparable utility as a signature isotope. 


\section{REFERENCES}

[0] "Potential Applications of Environmental Sampling and Analysis for the IAEA"

E. Raber

presented at the IAEA Consultants Meeting, March 1993

[1] "The detection of environmental signatures from covert nuclear fuel reprocessing"

A. McMahon, P. Roberts, K. Nicholson, J. Toole, D. Wickendon, J. Watterson and I. Adsley

AEA Technology, March 1993.

[2] "Wide-Area Monitoring to Detect Undeclared Nuclear Factilities"

N. A. Wogman, et al.

PNL-SA-24889

[3] "Detection of Undeclared Plutonium Production (Reactor Operations/Fuel Reprocessing)"

R. W. Perkins and N. A. Wogman

PNL

[4] "PXAMS-Projectile $X$ ray AMS: $x$ ray yields and applications"

J.E. McAninch, G.S. Bench, S.P.H.T. Freeman, M.L. Roberts, J.R. Southon, J.S. Vogel and I.D. Proctor Nuclear Instruments and Methods B 99, 541 (1995).

[5] "Development of ${ }^{129} 1$ AMS for the LLNL Spectrometer"

I.D. Proctor, J.R. Southon and M.L. Roberts

Nuclear Instruments and Methods B 92, 92 (1994).

[6] "Technetium in the Nuclear Fuel Cycle, in Medicine and in the Environment"

K.H. Lieser

Radiochimica Acta 63, 5-8 (1993).

[7] "Technetium in Nature and Age of the Solar System"

P. K. Kuroda

Radiochimica Acta 63, 9-18 (1993)

[8] "Ultratrace Analysis of Technetium"

N. Trautmann

Radiochimica Acta 63, 37-43 (1993)

[9] "Determination of Technetium by Laser Induced Photoacoustic Spectroscopy Coupled with WaveLength Shifter Method"

T. Fujita, T. Sekine, H. Hiraga, K. Yoshihara, A. Mutalib, R. Alberto and J.I, Kim

Radiochimica Acta 63, 45-47 (1993)

[10] "Radioanalytical Studies of Tc in the Environment: Progress and Problems"

E. Holm

Radiochimica Acta, 63, 57-62 (1993).

[11] "Determination of Technetium-99 in Environmental Samples by Inductively Coupled Plasma Mass Spectrometry"

S. Morita, K. Tobita, and M. Kurabayashi

Radiochimica Acta 63, 63-67 (1993) 
[12] "Separation Procedure for the Determination of Technetium-99 in Soil by ICP-MS" K. Tagami and S. Uchida

Radiochimica Acta 63, 69-72 (1993)

[13] "Analytical Procedure fir Technetium-99 in Seawater by ICP-MS"

N. Momoshima, M. Sayad, and Y. Takashima

Radiochimica Acta 63, 73-78 (1993)

[14] "Concentrations of Technetium-99 in Marine Algae and Seawater"

S. Hirano and M. Matsuba

Radiochimica Acta 63, 79-82 (1993)

[15] "Determination of Technetium-99 and Neptunium-237 in Environmental Samples by Inductively Coupled Plasma Mass Spectrometry"

Sh. Sumiya, Sh, Morita, K. Tobita, and M. Kurabayashi

Journal of Radioanalytical and Nuclear Chemistry 177, 149-159 (1994).

[16] "Application of a High Resolution Inductively Coupled Mass Spectrometer to the Measurement of Long-Lived Radionuclides"

C. Kim, R. Seki, S. Morita, S. Yamasaki, A. Tsumura, Y. Takaku, Y. Igarashi and M. Yamamoto Journal of Analytical Atomic Spectrometry 6, 205-209 (1991)

[17] "The determination of low levels of ${ }^{99} \mathrm{Tc}$ in environmental samples by inductively coupled plasmamass spectrometry"

S. Nicholson, T.W. Sanders and L.M. Blaine

The Science of the Total Environment 130-131, 275-284 (1993)

[18] "Quantitative Detection of Strontium-90 and Strontium-89 in Environmental Samples by Laser Mass Spectrometry"

K. Wendt, G. Haub, S. Köhler, H.-J. Kluge, L. Monz, E.-W. Otten, G. Passler, P. Senne, J. Stenner, K. Zimmer, G. Herrmann, N. Trauttmann and K. Walter

in Optoelectronics for Environmental Science, Eds. S. Martellucci and A. N. Chester, Plenum Press, New York (1989).

[19] "Trace Analysis of Plutonium and Technetium by Resonance Ionization Mass Spectrometry using an Atomic Beam and a Laser Ion Source"

F. Ames, H.-J. Kluge, E.-W. Otten, B. M. Suri, A. Venugopalan, G. Herrmann, J. Riegel, H. Rimke, P. Sattelberger, N. Trauttmann and R. Kirchner

in Optoelectronics for Environmental Science, Eds. S. Martellucci and A. N. Chester, Plenum Press, New York (1989).

[20] "Atmospheric Transport Processes, Part 4: Radioactive Tracers"

E. R. Reiter

Technical Information Center, U.S. Department of Energy (1978)

[21] "99 Tc in the Sub-arctic Food Chain Lichen-Reindeer-Man"

E. Holm and J. Rioseco

Journal of Environmental Radioactivity 5, 343-357 (1987)

[22] "Determination of picogram amounts of "Tc by Neutron Activation Analysis"

S. Foti, E. Delucchi and V. Akamian

Analytica Chimica Acta 60, 261-268 (1972) 
[22b] "Determination of picogram amounts of Technetium in environmental samples by Neutron Activation Analysis"

S. Foti, E. Delucchi and V. Akamian

Analytica Chimica Acta 60, 269-276 (1972)

[23] "Mass spectrometry of Technetium at the subpicogram level"

D.J. Rokop, N.C. Schroeder and N.C. Wolfsberg

Analytical Chemistry 62, 1271-1274 (1990)

[24] "Radiochemical measurements of ${ }^{99} \mathrm{Tc}$ : sources and environmental levels"

E. Holm, J. Rioseco, S. Ballestra and A. Walton

Journal of Radioanalytical and Nuclear Chemistry, Articles 123, 167-179 (1988)

[25] "Origin of technetium-99 and its use as a marine tracer"

A. Aarkrog, L. Carlsson, Q.J. Chen, H. Dahlgaard, E. Holm, L. Huynh-Ngoc, L.H. Jensen, S.P.

Nielsen, $\mathrm{H}$. Nies

Nature 335, 338-340 (1988)

[26] S. Hirano, M. Matsuba, H. Kamada

Radioisotopes 38, 186 (1989)

[27] "A resonance ionization mass spectrometer as an analytical instrument for trace analysis"

W. Ruster, F. Ames, H.-J. Kluge, E.-W. Otten, D. Rehklau, F. Scheerer, G. Herrmann, C. Mühlbeck, J. Riegel, H. Rimke, P. Sattelberger and N. Trautmann

Nuclear Instruments and Methods A281, 547-558 (1989)

[28] "Separation and Detection of Trace Amounts of Technetium"

P. Sattelberger, M. Mang, G. Herrmann, J. Riegel, H. Rimke, N. Trautmann, F. Ames and H.-J.

Kluge

Radiochimica Acta 48, 165-169 (1989)

[29] "A High-Temperature Laser Ion Source for Trace Analysis and Other Applications"

F. Ames, T. Brumm, K. Jäger, H.-J. Kluge, B.M. Suri, H. Rimke, N. Trautmann and R. Kirchner Applied Physics B51, 200-206 (1990)

[30] "A Negtive Ion Cookbook"

R. Middleton

University of Pennsylvania

October, 1989.

[31] "Migration of Technetium-99 in Alluvial Aquifer at the Alluvial Aquifer at the Nevada Test Site, Nevada"

N. C. Schroeder, D. Morgan, D.J. Rokop and J. Fabryka-Martin

Radiochimica Acta 60, 203-209 (1993)

[32] "Methods for the Separation of Technetium from Ruthenium for Inductively Coupled Plasma-Mass Spectrometry"

Ihsanullah

Separation Science and Technology 29, 781-797 (1994).

[33] "41 Ca: Measurement by accelerator mass spectrometry and applications"

D. Fink, R. Middleton, J. Klein and P. Sharma

Nuclear Instruments and Methods B47, 79-96 (1990) 
[34] "Strontium-90 in Environmental Samples from Northern Germany before and after the Chernobyl Accident"

R.-D. Wilken and R. Diehl

Radiochimica Acta 41, 157-162 (1987) 